\title{
Assessing the progress of river restoration in the UK: has ecological condition improved over two decades of intervention?
}

\section{Harriet Elizabeth Moore ( $\sim$ HaMoore@lincoln.ac.uk)}

University of Lincoln - Brayford Campus: University of Lincoln https://orcid.org/0000-0003-1941-6471

Theresa Mercer

University of Lincoln - Brayford Campus: University of Lincoln

Dilkushi de Alwis Pitts

University of Lincoln - Brayford Campus: University of Lincoln

\section{Sam Beagley}

University of Lincoln - Brayford Campus: University of Lincoln

\section{Marc Naura}

River Restoration Centre

\section{Alex Bryden}

River Restoration Centre

\section{Research Article}

Keywords: Habitat condition, ecological condition, Water Framework Directive, River Restoration, monitoring and assessment

Posted Date: March 15th, 2021

DOI: https://doi.org/10.21203/rs.3.rs-325336/v1

License: (c) (i) This work is licensed under a Creative Commons Attribution 4.0 International License. Read Full License 


\section{Abstract}

Context: Habitat condition indicates the immediate success of efforts to revegetate degraded river basins as well as longer-term progress towards improving water quality. In the context of the Water Framework Directive, habitat condition in the UK also reflects how well international environmental policy translates into improved river management domestically. Objectives: 1 . To assess whether habitat condition in the UK has improved or declined over the past two decades, 2. To assess whether regions identified by the first WFD assessment have improved or declined. Methods: Statistical and spatial analysis of more than 25,000 habitat condition records collated in the River Habitat Survey over the 1990s and 2000s. Computation of an Index of Change demonstrating the improvement or decline of habitat quality in Local Authorities. Comparison of Indices of Change with a sub-sample of 1,727 WFD assessments conducted in 258 Local Authorities. Results: Measures indicate that habitat quality has declined. Riparian quality has improved. 27 regions were identified with the worst declining quality. Condition has declined most substantially in regions that were previously in 'good' condition. Conclusion: Priorities for future investment should include improving degraded sites, protecting high quality sites, and increasing monitoring of 'data poor' regions. We offer a framework for decision making, including distinguishing the underlying cause of quality decline. Habitat quality decline in the UK mirrors the experience of European nations and points to systemic challenges associated with implementing international water policy in a national context.

\section{Introduction}

Many of the biggest environmental challenges facing societies involve managing resources in river basins, and mitigating the negative impacts of development and emerging threats, such as water over-extraction (Kingsford 2000; Palmer et al. 2008), declining water quality (Dawson et al. 2015; Lutz et al. 2016), contaminants (Coulthard \& Macklin 2003; Macklin et al. 2006) and habitat loss (Reid et al. 2019). River restoration involves designing and implementing projects, practices and infrastructure to address degradation, such as revegetation projects that aim to improve habitat condition in the short term and improve water quality in the longer term (Wohl et al. 2015). Other common river restoration projects include building fish ladders on dams to promote fish migration and breeding (O'Brien et al. 2010), constructing fences on riverbanks to prevent cattle access to improve water quality and reduce bank erosion from trampling (Brooks \& Lake 2007; Kondolf et al. 2007), and reintroducing woody debris to river channels to improve riverbed morphology (Erskine \& Webb 2003). After three decades of investment in such projects, river researchers recognize the need to monitor and assess ecological condition in order to advance the field of river restoration (Bernhardt et al. 2007; Kondolf et al. 2007; Morandi et al. 2014).

Monitoring, assessment and record-keeping post-restoration is not straightforward. The most obvious measures of improvement, such as water quality, can take years or even decades to change in response to restoration projects (Hamilton 2012; Meals et al. 2010). This is because instream recovery trajectories are influenced by land use in wider catchments as well as individual projects; the impact of restoration is cumulative. Other approaches to monitoring and assessment involve measuring ecological components of restoration with more immediate recovery trajectories, such as vegetation and habitat condition, which is an interim 'proxy' indicator of water quality improvement over the longterm (Ward et al. 2006). For example, the percentage of riparian vegetation cover on riverbanks (e.g. Stone et al. 2005), and habitat condition (Heatherly et al. 2007) have been found to be positively related to instream water quality. Proxy measures of water quality can also include hydromorphological characteristics, naturalness, the presence of ecosystem friendly features, and the biodiversity profile of biota such as macroinvertebrates (Mercer et al. 2014; Dosskey et al. 2010; Vaughan \& Ormerod 2010). 
Common challenges for monitoring and assessing the progress of river restoration are related to data quality, including recording errors (taxonomic and transcription), and inconsistent data collection between multiple surveyors over time (Vaughan \& Ormerod 2010). These issues transcend individual river basins or countries. National assessments of the progress of river restoration have been conducted in regions including North America (Bernhardt et al. 2007, 2005; Palmer et al. 2010) and Australia (Brooks \& Lake 2007; Moore \& Rutherfurd 2017; Moore et al. 2018) using databases of projects established over the past 30-50 years. For example, in 2005 a project was undertaken in the United States of America to summarize and assess the progress of river restoration. The result was a database, the National River Restoration Science Synthesis (NRRSS), including records of more than 37,000 projects compiled from more than 60 national and regional sources and agencies. Of these records, only $10 \%$ included any mention of monitoring (Bernhardt et al. 2005), and little information was found related to the ecological effectiveness of restoration (Palmer et al. 2007). Similarly, of more than 5,000 river restoration projects recorded in the UK National River Restoration Inventory (NRRI), only $21 \%$ of records indicated that follow-up monitoring and assessment of existing projects has been undertaken (England et al., 2019), and where monitoring had been undertaken, results were often inconsistent (Smith et al. 2014).

Despite these limitations, Vaughan \& Ormerod (2010) suggest there is considerable value in analysing large regional or national datasets as the size, geographic and temporal spread of the data, are likely to overcome many of the weaknesses associated with data quality. Here we report our analysis of a comprehensive national dataset collated between 1994 and 2011 by multiple organisations, although primarily the UK Environment Agency (EA) including more than 25,000 assessments of vegetation condition in river basins, known as the River Habitat Survey (RHS). This unique dataset was collated over two periods; the first period in which assessments were conducted between was 1994 and 1996 and the second period was between 2007 and 2008. The RHS was undertaken to build a national inventory of habitat features, and to assess the condition of river habitats after two decades of investment in river restoration projects (RHS, 2018). The RHS was not intended to monitor or assess the effectiveness of individual river restoration projects. Rather, the purpose was to examine the overall outcomes of coordinated efforts to improve the ecological condition of degraded river systems. Several noteworthy studies have drawn on the NRRI database to consider trends in river restoration techniques (e.g., Cashman et al. 2019) and the RHS database to examine the relationship between river restoration projects and channel morphology (Smith et al. 2014). These studies have demonstrated that reduction methods, such as collapsing or averaging data across multiple sites within a region, can be used to make meaningful use of ecological measures which are inconsistent or incomplete across the entire dataset (e.g., Moore \& Rutherfurd 2019; Smith et al. 2014).

Assessing whether the ecological condition of river basins has improved over two decades of restoration is necessary to identify successful strategies and potential challenges, thus advancing the field of river restoration (Kondolf et al. 2007). However, the need to evaluate progress in the UK is also apparent in the context of international environmental policy, including the European Union Water Framework Directive (WFD). The WFD was introduced in 2000, including the first assessment of UK river systems that involved scoring habitat condition as 'high', 'good', 'moderate', 'poor' or 'bad'. Assessment scores are recorded in the NRRI database. Of 1,727 habitat quality assessments conducted, $36 \%$ of sites were in 'poor' or 'bad' condition, 49\% were in 'moderate' condition, 32\% were in 'good' condition, and only one site was considered to be of 'high' quality. Two decades later, policymakers are considering whether international efforts to guide ecological restoration in river basins has been successful. Restoring habitat for wildlife, improving the ecological condition, and achieving clean and plentiful water are also important national priorities and form the cornerstones of the UK Government '25 Year Environmental Plan' (DEFRA 2018).

In this paper we assess the progress of river restoration in the UK using the RHS database and WFD assessment scores recorded in the NRRI. To date there has been no comprehensive analysis of the progress of river restoration in the UK with regards to observable changes in ecological condition. Our approach is two-fold. The first purpose of the research 
was to compare habitat condition assessments conducted in the 1990s to those assessments conducted in the 2000 s to determine whether change has occurred, and if change reflects improved or worsening ecological condition.

The RHS database includes six measures of habitat condition which reflect a degree of modification of the natural environment, habitat quality, and the quality of riverbank (riparian) vegetation. In the absence of widespread monitoring and assessment of individual river restoration projects, this unique dataset offers the opportunity to explore the effectiveness of river restoration on a national scale. We computed an 'Index of Change' to examine whether the average scores recorded for four of these measures within UK Local Authority (LA) regions have changed between the rounds of assessment conducted in the 1990s and those conduced in the 2000s. This analysis involved employing data reduction methods (e.g., Moore \& Rutherfurd 2019) to overcome limitations, such as the fact that the number and location of sites assessed in each LA vary between datasets collated in the 1990s and those collated in the 2000 s.

The second purpose of the research was to explore whether ecological changes over the past decade are in line with recommendations following the first WFD assessment of habitat and water quality. We consider that vegetation condition, including measures of habitat quality and riverbank, or 'riparian' cover, are 'proxy' measure of future water quality, and thus reflect progress towards achieving the objectives of the WFD. Ecological improvement also reflects how well the river restoration sector is addressing the aims of ambitious international policy, including the WFD. Thus, we compared WFD scores with habitat condition scores from the second round of condition assessment. This approach allowed us to identify whether regions with 'poor' or 'bad' water quality have improved. Following this analysis, we offer some suggestions for optimizing the outcomes of river restoration and achieving the objectives of international policy.

\section{Methods}

The research involved an assessment of habitat condition data collated in the RHS database, and WFD condition scores reported in the NRRI. Three main research methods were utilized to address our research questions; statistical computation of an Index of Change, spatial visualization of the Index, and ground-truthing of RHS assessments. Ground truthing surveys were carried out in the summer of $2019(28 / 8 / 19)$ to improve our understanding and interpretation of RHS data. The methods and results are reported in supplementary material.

\subsection{Research Aims and Questions}

The first aim of the research was to assess the records collated in the RHS database and determine whether change has occurred between the 1990s and 2000s across four habitat quality measures recorded in the RHS undertaken by the EA. This involved computing and mapping an Index of Change to identify which Local Authority regions could be a high priority for future restoration efforts. The second aim was to compare the assessment of habitat condition undertaken in accord with the WFD with measures recorded in the RHS throughout the 2000s, specifically to determine whether regions with sites in 'moderate', 'poor' or 'bad' condition have improved, and whether regions with sites in 'good' or 'high' condition remain in these conditions.

\subsection{Data handling and cleaning}

To determine whether ecological condition has improved over two decades of river restoration in the UK, we examined four measures of habitat condition collated in the RHS database; Habitat Quality Assessment Index (HQA), River Habitat Quality (RHQ) Index and Riparian Quality Index (RQI). Two measures, Habitat Modification Score (HMS) and Channel Re-sectioning Index (CRI) were excluded from our analysis for two reasons. Firstly, in most cases, modification infrastructure, such as dams, and modification processes, such as channelization, are unlikely to have been removed or reversed over the period of data collection considered in our research. In the UK, barrier removal, including dams and 
weirs, and channel remeandering projects, are much less common than projects that involve revegetation for ecological restoration. Of nearly 5,000 restoration projects undertaken in the UK over the past three decades, approximately 1,100 projects have involved barrier removal and less than 100 have involved re-meandering (NRRI dataset, River Restoration Centre (2018)), while approximately $40 \%$ involve ecological restoration and revegetation. Secondly, ideally, a BeforeAfter research design involves comparing two scores from the same site. However, the assessments conducted in the 2000s were undertaken at different sites compared to those undertaken in the 1990s. Thus, we used a data reduction method to compute an average score for each measure at the Local Authority scale. While imperfect, data reduction of this nature is a common approach for analysing large-scale ecological data in river basins (e.g. Moore \& Rutherfurd 2019; VCMC 2017). This is because the practices and procedures employed by river basin management authorities often change over time, or vary between regional authorities (Smith et al. 2014). In some cases, such as vegetation condition within a region (e.g. Moore \& Rutherfurd 2019), data reduction can offer meaningful insight (Smith et al. 2014). However, in the case of physical modification, it is impossible to compute an average score when one site within a region may contain a dam wall while others may not.

To examine whether ecological condition has improved since the first WFD assessment, we computed an average WFD score for all site condition assessments conducted for LA regions and compared our Index of Change with WFD scores. For some LAs, scores were only recorded in the RHS database and not the WFD database. Thus, we reduced the combined dataset to include only LA regions with scores in both databases; in total, 258 LA regions were included in the final analysis, comprising 1,727 WFD assessments.

\subsection{Measures}

\section{River Habitat Surveys}

The River Habitat Survey (RHS) database contains more than 25,000 records of assessments undertaken between 1997 and 2011. Each assessment was conducted by surveyors accredited by the EA, including EA staff, local authorities, and members of private agencies. The original survey was designed and run by the National Rivers Authority, then EA. The EA trained and accredited several hundred RHS surveyors. From 1994 to 1996 and from 2007 to 2008, 9,000 RHS sites in England and Wales were selected using a stratified random sample design. Sites in Scotland and Northern Ireland were included in surveys conducted in the 1990s but were discontinued in the 2000s. In 19941996, the basis for the sampling was the 250k scale river network and sites were selected using the Ordnance Survey (OS) $10 \mathrm{~km}$ grid. Three RHS sites were selected randomly using a smaller $2 \mathrm{~km}$ grid within each $10 \mathrm{~km}$ square resulting in a total of 4523 sites. In 2007-8, the same process was repeated but only two sites were selected on the 250k network and one site was selected on river stretches from the $50 \mathrm{k}$ network outside the $250 \mathrm{k}$ network boundaries. This combined sampling strategy accounted for headwater streams which were under-represented in the previous sample. The remaining sample of more than 1,500 sites were selected following a near-random process for the purpose of targeting priority rivers and catchments.

Assessment involved recording morphological and ecological features, including bank and channel structure, artificial modification, surrounding land use, and vegetation structure, along a $500 \mathrm{~m}$ reach of a priority river in the UK (Environment Agency 2003). Measures of these features were collated into four scores and indices represented by five discrete five-point Likert-type scales. The characteristics, methodology and calculation of the individual indices for habitat quality and hydromophological indices are summarised in Table 1. For the Habitat Quality Assessment (HQA) and Riparian Quality Index (RQI), the scale of 1-5 reflects a progression from bad condition to good condition. For the River Habitat Quality (RHQ) index and Hydromorphological Impact Ratio (HIR), the scale of 1-5 is inverse, with 1 representing a good condition and 5 representing a bad condition (RRC 2020). 
Table 1

RHS habitat quality and hydromorphological indices (RRC 2020). Note for ranges, green signifies positive end of the range, red signifies negative end of the range.

\begin{tabular}{|c|c|c|c|c|}
\hline RHS index & Range & Description & Measures & Calculation of index \\
\hline $\begin{array}{l}\text { Habitat Quality } \\
\text { Assessment score } \\
\text { class (HQA) }\end{array}$ & $\begin{array}{l}1 \\
\text { (very low) } \\
\text { to } \\
5 \\
\text { (very } \\
\text { high) }\end{array}$ & $\begin{array}{l}\text { The presence, } \\
\text { diversity and } \\
\text { naturalness of } \\
\text { habitat features } \\
\text { that are known to } \\
\text { benefit local wildlife } \\
\text { compared to similar } \\
\text { sites. }\end{array}$ & $\begin{array}{l}\text { Flow types, natural channel } \\
\text { substrates, natural channel } \\
\text { features (e.g. mature } \\
\text { islands), natural bank } \\
\text { features (e.g. earth cliffs), } \\
\text { bank vegetation structure } \\
\text { (simple or complex), point } \\
\text { bars, in-stream channel } \\
\text { vegetation, land-use within } \\
50 \mathrm{~m} \text {, trees and associated } \\
\text { features, special features } \\
\text { (e.g. debris dams). }\end{array}$ & $\begin{array}{l}\text { Sub scores are given } \\
\text { to features observed } \\
\text { in each of the } \\
\text { categories based on } \\
\text { the presence of } \\
\text { features with higher } \\
\text { scores given to } \\
\text { features that are } \\
\text { considered more } \\
\text { 'natural'. Sub scores } \\
\text { are collated to } \\
\text { produce a final score. }\end{array}$ \\
\hline $\begin{array}{l}\text { River Habitat } \\
\text { Quality (RHQ) index }\end{array}$ & $\begin{array}{l}1 \\
\text { (excellent) } \\
\text { to } \\
5 \\
\text { (very } \\
\text { poor) }\end{array}$ & $\begin{array}{l}\text { The overall habitat } \\
\text { quality and } \\
\text { conservation value. }\end{array}$ & $\begin{array}{l}\text { Management prioritisation } \\
\text { resulting from this index } \\
\text { range from } 1 \text { (protect) to } 5 \\
\text { (restore). }\end{array}$ & $\begin{array}{l}\text { HQA and HMS } \\
\text { indices are } \\
\text { amalgamated into } \\
\text { one index and } \\
\text { compared against } \\
\text { benchmark (high } \\
\text { quality) sites in terms } \\
\text { of distance of the } \\
\text { HQA score to the } \\
\text { nearest benchmark } \\
\text { site using context } \\
\text { analysis. }\end{array}$ \\
\hline $\begin{array}{l}\text { Riparian Quality } \\
\text { Index (RQI) }\end{array}$ & $\begin{array}{l}1 \\
\text { (very low) } \\
\text { to } \\
5 \\
\text { (very } \\
\text { high) } \\
\text { or out of } \\
120\end{array}$ & $\begin{array}{l}\text { The complexity, } \\
\text { continuity and } \\
\text { naturalness of the } \\
\text { riparian vegetation } \\
\text { (area stretching } \\
\text { from the riverbank } \\
\text { face to } 5 \mathrm{~m} \text { away } \\
\text { from the bank top). }\end{array}$ & $\begin{array}{l}\text { Complexity: vegetation } \\
\text { structure (e.g. uniform/bare } \\
\text { to complex). Continuity: how } \\
\text { contiguous the vegetation } \\
\text { is. Naturalness: Evidence of } \\
\text { modification. }\end{array}$ & $\begin{array}{l}\text { Sub scores are given } \\
\text { to each of the } \\
\text { categories for } \\
\text { complexity, } \\
\text { naturalness and } \\
\text { continuity (max } 60, \\
40 \text { and } 20 \text { points } \\
\text { respectively). Scores } \\
\text { are collapsed to a } \\
\text { final score between } 1 \\
\text { and } 120 \text {. Higher } \\
\text { scores correspond to } \\
\text { better riparian quality. }\end{array}$ \\
\hline $\begin{array}{l}\text { Hydromorphological } \\
\text { Impact Ratio (HIR) }\end{array}$ & $\begin{array}{l}1 \\
\text { (low } \\
\text { impact) } \\
\text { to } \\
5 \\
\text { (very high } \\
\text { impact) }\end{array}$ & $\begin{array}{l}\text { The extent of } \\
\text { departure from } \\
\text { natural } \\
\text { hydromorphological } \\
\text { conditions. }\end{array}$ & $\begin{array}{l}\text { Hydromorphological } \\
\text { characteristics considered } \\
\text { include channel substrate, } \\
\text { flow regime, channel } \\
\text { vegetation and geomorphic } \\
\text { activity characteristics. }\end{array}$ & $\begin{array}{l}\text { The index is } \\
\text { measured as a ratio } \\
\text { and translated into a } \\
\text { 5-point scale. }\end{array}$ \\
\hline
\end{tabular}

Water Framework Directive assessments

The WFD habitat quality assessment scoring method combines two measures that are identical to those involved in the RHS, habitat modification and habitat quality, with a visual assessment of hydromorphological features. We used the WFD habitat quality measures to assess whether ecological condition has improved in regions identified through the WFD assessment as 'very poor', 'poor' and 'moderate', and whether those regions considered to be in 'good' or 'high' 
quality have remained so over the decade following the WFD assessment. Thus, research question one considers change in four measures of habitat condition over two decades of river restoration, while research question two considers whether a single measure, habitat quality, has improved since the introduction of the WFD.

\subsection{Data analysis}

Statistical analysis

Four t-tests were computed to address our first research question about whether ecological condition has improved between the 1990s and the 2000s, for the measures HQA, RHQ, RQI and HIR. Four One-Way ANOVAs were computed to address our second research question about whether change demonstrates progress compared to WFD condition assessment scores. Of 1,727 sites included in the WFD assessment only one was classed 'high' quality and 66 were classed as 'bad' quality. Therefore, we re-classified these data into three categories; 'good', 'medium' and 'poor', whereby 'good' was inclusive of the 'high' quality site and 'poor' was inclusive of the 'bad' quality sites. ANOVA was used to explore whether LAs with on average 'poor' or 'medium' condition at the time of the WFD assessment have improved, and whether LAs with on average 'good' condition continued to be in good condition. This was achieved by comparing our Index of Change scores (see Sect. 2.5.2 Indices of Change and Spatial Representation) for HQA, RHQ, RQI and HIR between LAs with sites in 'good', 'medium' and 'poor' condition.

The Index of Change and spatial representation

To identify high-priority regions for future restoration, we computed an Index of Change for each of four RHS habitat quality measures that indicates whether change for each measure was positive, negative, or no change. These indices were used to represent change spatially at the Local Authority scale. This involved five steps. The RHS database contains records of all habitat assessments conducted in the 1990s and 2000s. Records include spatial point data, specifically the Eastings and Northings coordinates for each site where the habitat condition assessment was undertaken. Thus, the first step involved converting these Easting and Northing coordinates to latitude and longitude values (using a standard batch conversion website https://gridreferencefinder.com/batchConvert/batchConvert.php ). The second step was to overlay the Easting and Northing on a Local Authority map in ArcGIS, join point data to Local Authority labels, and extract the joined data to produce an excel spreadsheet. For the third step, assessment records were divided by decade for the purpose of computing the Index of Change. The fourth step was data reduction. Average values for each measure were computed at the Local Authority scale. There was some variability for number of assessments conducted in each LA, as demonstrated in S-1. In some cases, comparative analysis was not possible at the LA scale as assessments were not conducted in both the 1990s and the 2000s. Therefore, 4 LA regions were removed from the RHQ index analysis, 8 LA regions were removed from the HIR index analysis, 74 LAs were removed from the RQI analysis. In total, 348 LAs were included in the final analysis. The fifth step was to compute the change index for each measure. For measures including HQA and RQI, this involved subtracting the average LA scores obtained during assessments undertaken in the 2000s from the average LA scores obtained from assessments undertaken in the 1990s. The outcome was a standardized score for each LA whereby negative values represent a decline in habitat condition, positive scores represent an improvement, and a score of 0 reflects 'no change'. However, the Likert-scale scores for the measure RHQ and HIR were on an inverse scale. Thus, we inverted negative and positive scores to produce a consistent Index of Change, allowing for comparison between each measure, and for visual identification of regions which could be a priority for future investment in habitat condition improvement. In addition, Man Whitney $U$ analyses were computed for each LA across each of four RHS measures to determine whether the changes captured by the Index of Change are statistically significant. We did not anticipate that many results would be significant at the LA scale. In most cases, the number of assessments conducted per LA, and the number of assessments conducted for a single LA between the 1990 s and 2000 s varies considerably. The Index of Change is

Page $7 / 23$ 
intended as an indicator of the direction of change across RHS measures. Statistical significance may point to LAs that require particular attention for restoration. However, we do not dismiss non-significant results which may reflect trends in the direction of change.

The habitat quality indices HQA, RHQ, RQI and HIR were mapped to display spatial variations. Spatial patterns for each year and the differences between the years were also mapped. In order to compare the Habitat indices with one another, the indices were normalized and projected onto one scale. The spatial data pertaining to the habitat quality indices were divided into positive, negative, zero and no data maps and then converted to raster data in order to assign a continuous colour palette within ArcGIS.

\section{Results}

\subsection{Descriptive results}

River Habitat Surveys and WFD assessments

In total, the RHS database contained 25,227 assessments, including 13,967 conducted in the 1990s and 11,280 conducted in the 2000s. A total of 1,727 WFD assessments were conducted in 2000. The Means (M) and Standard Deviations (SDs) for HQA, RHQ, RQI, HIR and WFD scores are reported in Table 2.

Table 2

Means (M) and Standard Deviations (SD) for River Habitat Survey measures, including scores from assessments conducted in the 1900s and 2000s for HQA, RHQ, RQI, HIR, as well as scores for WFD assessments conducted in the 2000s.

\begin{tabular}{|c|c|c|c|c|c|c|c|c|c|}
\hline & HQA & & RHQ & & RQI & & HIR & & WFD \\
\hline & 1990s & $2000 s$ & 1990s & $2000 s$ & 1990s & $2000 s$ & 1990s & $2000 s$ & $2000 s$ \\
\hline $\mathrm{N}$ & 12,301 & 11,279 & 12,300 & 10,563 & 4,499 & 4,862 & 11,840 & 9.822 & 1,727 \\
\hline M & 3.1 & 2.88 & 3.97 & 4.05 & 2.6 & 3.09 & 3.56 & 3.63 & 1.79 \\
\hline SD & .48 & .82 & .3 & .36 & .5 & .6 & .19 & .22 & .45 \\
\hline
\end{tabular}

The Index of Change

After aggregating RHS records, the Index of Change was computed for 348 LAs. The Means (M) and Standard Deviations (SDs) of Index of Change scores for HQA, RHQ, RQI and HIR are reported in Table 3.

Table 3

Means (M) and standard deviations

(SD) of Index of Change scores for

River Habitat Survey measures,

including HQA, RHQ, RQI and HIR.

\begin{tabular}{|ccccc|}
\hline & HQA & RHQ & RQI & HIR \\
\hline M & -.22 & -.07 & .5 & -.06 \\
\hline SD & .56 & .31 & 1.05 & .29 \\
\hline
\end{tabular}

\subsection{Has ecological condition improved between the 1990 s and 2000s?}


Four t-tests were computed to determine whether ecological condition has improved by comparing scores from habitat assessments undertaken in the 1990s with scores from those assessments undertaken in the 2000s.

The results for the t-test computed to compare index values for the measure 'Habitat Quality Assessment' (HQA) indicate that on average, index values from assessments conducted in the $2000 \mathrm{~s}(\mathrm{M}=2.88, \mathrm{SD}=0.82)$ are lower than scores from assessments conducted in the 1990s $(M=3.10, S D=0.48), t(710)=1.96, p=0.00$. Low scores reflect poor habitat quality while high scores reflect good habitat quality. Thus, HQA measures suggest that habitat quality has declined.

The results for the t-test computed to compare scores for the measure 'River Habitat Quality' (RHQ) indicate that there is no significant difference between scores from assessments conducted in the $2000 \mathrm{~s}(\mathrm{M}=4.04, \mathrm{SD}=0.36)$ and those conducted in the 1990s $(M=3.97, S D=0.3), t(702)=1.96, p=0.08$.

The results for the t-test computed to compare scores for the measure 'Riparian Quality Index' (RQI) indicate that scores from assessments conducted in the $2000 \mathrm{~s}(\mathrm{M}=3.09, \mathrm{SD}=0.58)$ are higher than scores for those assessments conducted in the 1990s $(M=2.59, S D=0.49), t(282)=1.96, p=0.00$. This suggests that ecological condition has improved in relation to RQI measures.

The results for the t-test computed to compare scores for the measure 'Hydromorphological Impact Ratio' (HIR) indicate that there is no difference between scores from assessments conducted in the $2000 \mathrm{~s}(\mathrm{M}=3.63, \mathrm{SD}=0.22)$ and those assessments conducted in the 1990s (M=3.6, SD =0.18), $\mathrm{t}(694)=0.06$.

\subsection{Which Local Authority regions are a high priority for future restoration efforts?}

Indices of Change were computed for four of the RHS quality measures to demonstrate if there was a positive, neutral or negative change for each measure between the surveys conducted in the 1990s and 2000s. In addition, the statistical significance of these changes for each LA across all four RHS measures was determined using nonparametric analyses of mediums. A total of 369 Man Whitney $U$ tests were computed for each of the four RHS measures to investigate whether the differences observed between scores from assessments conducted in the 1990s and scores from assessments conducted in the 2000s are statistically significant. Individual Man Whitney U tests results are reported in Supplementary Material (S-3) and summarised in Fig. 1 which displays the percentage of scores falling within each change category for the RHS measures. The solid colour component of the bar chart shows the proportion of all records of LAs where habitat condition has worsened (red), improved (green), or where no change has been observed (orange). The dotted component of the bar chart shows the proportion of all LAs where a statistical result was computed for the Man Whitney U Test. The diamond pattern component of the bar chart shows the proportion of Man Whitney U Test computations for which it was not possible to compute a statistical result due to small sample size.

The results of the t-tests conducted to determine whether habitat condition has improved are further reflected in the Index of Change scores. The results indicate that RQI has the largest percentage of positive changes across local authority regions $(52.13 \%)$ and smallest negative changes (16.31\%). Conversely, percentages across the HQA measures indicate the largest frequency of negative changes across Local Authority regions (64.89\%) and smallest positive changes (21.35\%).

The computed Index of Change scores for each RHS quality index were also spatially mapped according to Local Authority regions to identify those regions that are a high priority for future restoration efforts (Fig. 2). Those areas that have undergone negative changes are represented by red shading, with a bolder red shade corresponding to more 
negative values. The orange shading corresponds to those areas with no change. The green areas represent positive changes, with a bolder green shade representing more positive values. Areas that are white correspond to areas where data is missing.

These results are also reported in Table 4, including the best and worst performing Local Authorities with respect to how much river habitat condition has improved or deteriorated over time. A more detailed breakdown, including those Local Authorities with a 'neutral' Index of Change score (' $O$ '), and Man Whitney U tests exploring the statistical significance of differences between scores obtained from assessments conducted in the 1990s compared to scores from assessments conducted in the 2000s are reported in the supplementary material (S-3). 
Table 4

Lowest and Highest performing local authorities (LAs) according to Habitat Quality Assessment (HQA), River Habitat Quality (RHQ), Riparian Quality Index (RQI) and Hydromorphological Impact Ratio (HIR).

\begin{tabular}{|c|c|c|c|c|c|c|c|c|}
\hline & HQA & & RHQ & & RQI & & HIR & \\
\hline \multirow{10}{*}{$\begin{array}{l}\text { Lowest } \\
\text { performing } \\
\text { LAs }\end{array}$} & \multicolumn{3}{|c|}{ Score } & \multicolumn{2}{|l|}{ Score } & \multicolumn{2}{|l|}{ Score } & \multirow{2}{*}{$\begin{array}{l}\text { Score } \\
-1.3 \sim\end{array}$} \\
\hline & Rushmoor & $-2.5^{\star}$ & $\begin{array}{l}\mathrm{Na} \mathrm{h}- \\
\text { Eileanan } \\
\text { Siar }\end{array}$ & $-1.4^{\star \star \star}$ & Gateshead & -3.0 & Bury & \\
\hline & Fife & $-2.4 \sim$ & $\begin{array}{l}\text { Mole } \\
\text { Valley }\end{array}$ & $-1.1^{\star \star \star}$ & $\begin{array}{l}\text { East Riding } \\
\text { of Yorkshire }\end{array}$ & $-2.0 *$ & $\begin{array}{l}\text { Stockton- } \\
\text { on-Tees }\end{array}$ & $-0.9 \sim$ \\
\hline & South Ayrshire & $-2.3 \sim$ & Hounslow & $-1.0 \sim$ & Lewisham & $-2.0 *$ & Liverpool & $-0.9 \sim$ \\
\hline & Clackmannanshire & $-2.3 \sim$ & Wyre & $-0.9 * \star \star$ & $\begin{array}{l}\text { North } \\
\text { Lincolnshire }\end{array}$ & $-2.0 \sim$ & Hertsmere & $-0.8 \sim$ \\
\hline & South Lanarkshire & $-2.1 \sim$ & Falkirk & $-0.9 \sim$ & Reading & $-2.0 \sim$ & Copeland & $-0.8 \sim$ \\
\hline & Derby & $-2.1 \sim$ & & & Southampton & $-2.0 \sim$ & Luton & $-0.8^{\star}$ \\
\hline & Corby & $-2.1 \sim$ & & & Thanet & $-2.0 \sim$ & & \\
\hline & & & & & Warrington & $-2.0 *$ & & \\
\hline & & & & & $\begin{array}{l}\text { Welwyn } \\
\text { Hatfield }\end{array}$ & $-2.0 *$ & & \\
\hline \multirow{8}{*}{$\begin{array}{l}\text { Highest } \\
\text { performing } \\
\text { LAs }\end{array}$} & & & & & & & & \\
\hline & Falkirk & $2.1 \sim$ & Dartford & $1.4 \sim$ & Carlisle & $3.0 * \star \star$ & $\begin{array}{l}\text { North } \\
\text { Tyneside }\end{array}$ & $1.3 \sim$ \\
\hline & Slough & $1.5 \sim$ & $\begin{array}{l}\text { Merthyr } \\
\text { Tydfil }\end{array}$ & $1.2^{\star \star}$ & Craven & $3.0 \star \star \star$ & Hastings & $1.0 \sim$ \\
\hline & Brentwood & $1.3 \sim$ & Erewash & $0.9 \sim$ & Redbridge & $3.0^{*}$ & Elmbridge & $0.9 \sim$ \\
\hline & Gloucester & $1.2 \sim$ & Dudley & $0.7^{*}$ & Stockport & $3.0^{*}$ & Havant & $0.9 \sim$ \\
\hline & $\begin{array}{l}\text { Kingston upon } \\
\text { Thames }\end{array}$ & $1.0 \sim$ & $\begin{array}{l}\text { Kingston } \\
\text { upon Hull, } \\
\text { City of }\end{array}$ & $0.7 \sim$ & & & Brent & $0.8 \sim$ \\
\hline & Lincoln & $1.0 \sim$ & & & & & & \\
\hline & $\begin{array}{l}\text { Oadby and } \\
\text { Wigston }\end{array}$ & $1.0 \sim$ & & & & & & \\
\hline \multicolumn{9}{|c|}{ *non-significant change } \\
\hline \multicolumn{9}{|c|}{${ }^{* *}$ change significant at $p<.05$} \\
\hline
\end{tabular}




\subsection{Does change reflect progress in the context of the first WFD assessment?}

Four one-way ANOVAs were computed to compare change indices for habitat quality scores between sites categorized in the WFD assessment as 'poor', 'moderate', and 'good' to investigate whether high-priority degraded sites have improved, and also whether sites in 'moderate' or 'good' condition have been maintained to these standards.

Table 5 demonstrates that there was a significant difference in change indices between 'poor', 'moderate', and 'good' sites for the HIR index There was no difference between change indices in these categories for all other measures.

Table 5

ANOVAs comparing change indices for habitat quality scores between sites categorized in the WFD assessment as 'poor',

\begin{tabular}{|c|c|c|c|c|}
\hline & & df & $F$ & Sig. (p) \\
\hline \multirow[t]{3}{*}{ HQA Change } & Between Groups & 2 & .565 & .569 \\
\hline & Within Groups & 1244 & & \\
\hline & Total & 1246 & & \\
\hline \multirow[t]{3}{*}{ RHQ Change } & Between Groups & 2 & .576 & .562 \\
\hline & Within Groups & 1240 & & \\
\hline & Total & 1242 & & \\
\hline \multirow[t]{3}{*}{ RQI Change } & Between Groups & 2 & 1.418 & .243 \\
\hline & Within Groups & 960 & & \\
\hline & Total & 962 & & \\
\hline \multirow[t]{3}{*}{ HIR Change } & Between Groups & 2 & 5.622 & .004 \\
\hline & Within Groups & 1238 & & \\
\hline & Total & 1240 & & \\
\hline
\end{tabular}

Table 6 displays the mean change between 1990s and 2000s scores for each measure. Positive values reflect improvement and negative values reflect deterioration. Change values for the measures HQA, RHQ and HIR indicate that on average, sites in all categories have declined. For HQA and HIR sites in 'good' condition show a larger decline than sites in either the 'moderate' or 'poor' classes. In contrast, average change values for the measure RQI indicate that all sites in all categories have improved. However, except for HIR, these changes were not found to be statistically significant (Table 5). 
Table 6

Mean change between 1990s and 2000s scores for 'poor', 'moderate' and 'good' assessments in the WFD. Grey shading highlights the changes for HIR which are statistically significant $(\mathrm{P}<.01)$.

\begin{tabular}{|lllll|}
\hline \multirow{2}{*}{ HQA Change } & & N & Mean & SD \\
& Poor & 458 & -.24 & .52 \\
\cline { 2 - 6 } & Moderate & 606 & -.1 & 3.37 \\
\cline { 2 - 6 } & Good & 183 & -.25 & 2.37 \\
\hline RHQ Change & Poor & 456 & -.09 & .28 \\
\cline { 2 - 5 } RQI Change & Moderate & 604 & -.1 & .24 \\
\cline { 2 - 5 } & Good & 183 & -.07 & .29 \\
\cline { 2 - 5 } & Moderate & 490 & 10.27 & 23.29 \\
\cline { 2 - 5 } HIR Change & Good & 136 & 8.78 & 23.84 \\
\cline { 2 - 5 } & Poor & 454 & -.0486 & .25 \\
\cline { 2 - 5 } & Moderate & 604 & -.0865 & .25 \\
\cline { 2 - 5 } & Good & 183 & -.1143 & .22 \\
\cline { 2 - 5 } & & & & 23.86 \\
\hline
\end{tabular}

\section{Discussion}

\subsection{Has ecological condition improved?}

The River Habitat Surveys conducted in the 1990s were intended to provide a baseline for future habitat quality assessment, and a basis for monitoring future morphological changes (Raven et al. 2000). Our analyses of surveys undertaken in the 1990s and in the 2000s suggest that overall, habitat quality has significantly declined (HQA) while riparian quality has significantly improved (RQI). Our finding about the decline of habitat quality reflects wider trends observed across the UK (Haines-Young et al. 2000; Smart et al. 2008).

In contrast to habitat quality, our results about riparian quality are inconsistent with wider research about the declining ecological quality of river systems; our findings suggest that riparian quality has significantly improved across the UK. One likely explanation for this is related to how riparian quality is measured using the RHS. The RQI index scores the naturalness, continuity and complexity of riparian zones (RRC 2020). Importantly, this approach doesn't account for whether species occurring in the riparian zone are native or invasive. For example, a stretch of riverbank may be scored highly for complexity and continuity based on the presence of multiple invasive species, such as Impatiens glandulifera (Himalayan balsam) despite the absence of native species that comprise healthy habitat. This oversight reflects a more general challenge within the river basin management industry. Measures of riparian improvement tend to focus on the function of vegetation for morphological condition, such as bank stabilization. Where ecological condition is taken into account measures are often limited to single processes or features, such as vegetation structure and continuity (de Sosa et al. 2018). As such, the full complexity of ecosystems are rarely assessed (England et al. 2019). 
River restoration in the UK is guided by best practices (RRC, 2014), including methods for riparian management which are well documented (Mercer et al. 2014; de Sosa et al. 2018; Vidon et al. 2019). Monitoring and assessment feeds back into the design and implementation of future projects, and the evolution of best practices in response to the changing dynamics of river systems. Using measures that do not reflect key elements of ecological condition, such as the proportion of exotic compared to native vegetation (Hulme \& Bremner, 2006), constrains the usefulness of the RHS as an assessment tool, and presents a challenge for determining the true condition of riparian areas in the UK.

Our observations about assessing riparian condition are indicative of shifting priorities in river management, rather than a reflection of poor methodological design. In the early days of the river restoration movement, a central goal in the UK (Harper et al. 1999), America (Bernhardt et al. 2007) and elsewhere (Hubble et al. 2010) was revegetating denude and degraded riverbanks. In this context, measuring vegetation cover without distinguishing between exotic and native species has been an effective way of assessing morphological recovery, such as bank stabilization and erosion control. After two decades of practice and policy, the goals of restoration have diversified and include enhancing biodiversity. Invasive species in riparian zones out-compete native species in riverine ecosystems, transform nutrient cycling and alter interspecific interactions related to the habitat function of vegetation (Robertson \& Coll 2019). Thus, there is a need to revisit the measures and criteria for riparian quality included in the RHS.

\subsection{Regional priorities for future restoration and investment}

Based on our analysis of aggregate habitat conditions scores within local authorities, we have identified 27 local authorities in which condition has declined between initial assessments conducted in the 1990s and the most recent round of assessments conducted in the 2000s. However, in most cases change was not statistically significant. We conducted analyses to determine whether change was statistically significant for each LA across all four measures of habitat condition. For each measure, a proportion of analyses could not be computed due to small sample size below the threshold for statistical power ( $N=50$ per $L A$ ). These proportions were: $17 \%$ for HQA, $21 \%$ for RHQ, $19 \%$ for RQI and $35 \%$ for HIR. Thus, on average less than $23 \%$ of all Index of Change scores were unable to be analysed statistically. Further, of Index of Change scores that were computed, less than $20 \%$ of changes proved to be statistically significant. Those changes that were significant were exclusively cases where change was either 'positive' or 'negative'; no cases of 'no change' were significant. Thus, while the changes reported here reflect trends and can serve as interim measures of progress towards longer-term restoration goals, our findings should be interpreted cautiously.

The most notable changes are a decline in measures of HQA, related to habitat diversity and naturalness, and RQI, related to riparian vegetation quality and complexity, with an Index of Change range of between -2 and -3 . Thus, while riparian quality has improved overall, the degree of decline in some regions has been substantial. By comparison, changes to measures of HIR, related to hydromorphological conditions, and RHQ, related to the extent of modification (e.g., channelization and instream infrastructure), were more moderate with an Index of Change range of between - 0.8 and - 1.4. Thus, the morphological characteristics of rivers and streams, such as channel form, have undergone less significant transformations over the past two decades compared to the ecological characteristics, such as vegetation diversity. These trends reflect the historic legacy of channel modification in the UK; most major morphological and infrastructural changes to river systems took place in the early 19th century. Compared to past eras, there are few opportunities for channelization, impoundment and diversion in contemporary times. In contrast, ongoing development continues to degrade native vegetation and reduce habitat quality in rural (Ridding et al., 2020) and urban (McKinney, 2008) landscapes. Thus, improving habitat and vegetation quality, complexity, and naturalness should be key criteria for prioritising regional investment in future river restoration projects. Giving precedence to ecological condition would also support efforts to improve water quality and achieve the objectives of the WFD. 
Importantly, the nature of declining habitat condition, and the probable causes of decline, are highly place-specific, as demonstrated by the four maps presented in Fig. 2. For example, differences in Index of Change scores between regions along the east coast may reflect the characteristics of economic activity. A case in point is the Humber Estuary on the north east coast. The estuary borders the East Riding of Yorkshire and Lincolnshire and is the site of a Ramsar wetland as well as three large trade ports. Our Index of Change scores indicate that these regions have experienced some of the most severe declines in habitat condition between the 1990s and 2000s. The northern border, Yorkshire, has experienced habitat diversity decline (HQA) and increased modification (RHQ). By comparison, the southern border of North Lincolnshire has experienced an improvement in habitat diversity and naturalness and no change to modification. In both cases, riparian vegetation quality has declined markedly. However, habitat loss and modification in the Yorkshire region compared to habitat improvement and no change to modification in North Lincolnshire reflects the degree of economic activity around ports; the port of Hull in Yorkshire services a significantly larger urban area than the ports of Grimsby and Immingham in North Lincolnshire. Thus, the wider economic landscape and urban dynamics, among other factors, are likely to influence the progress of river restoration and habitat condition (McKinney, 2008). These trends may also reflect development in urban landscapes over the past two decades that impact habitat quality.

Exploring the complexity of local factors that explain declining habitat quality across the UK is beyond the scope of the current paper. Further research, including case studies of high-value regions, is needed to elucidate the relationship between habitat quality and factors including economic activity, urbanisation and rurality, as well as institutional arrangements such as the financial capacity of responsible agencies to invest in the establishment and ongoing maintenance of restoration projects (Moore \& Rutherfurd, 2017). However, we have some suggestions for prioritising future investment into restoration efforts. Others have presented guidelines and recommendations for selecting sites and projects for establishing river restoration projects to optimise ecological benefits (Jansson et al., 2007), minimise immediate and long-term costs (Moore \& Rutherfurd, 2017), as well as balancing social, economic and environmental values (Beechie et al., 2008). We emphasise the importance of a catchment-wide approach to identify the 'upstream', or underlying causes of declining habitat quality. In some cases, such as regions with rising population, habitat loss may be the irreversible consequence of urban development. In other regions where population and infrastructure remain relatively stable, there may be more realistic opportunities for habitat improvement.

We suggest that there are three equally important priorities for future investment to improve habitat condition and meet the requirements of the WFD regarding water quality. The first priority is to protect the condition of regions with highquality sites. The second priority is to improve the condition of regions with degraded sites that a) optimise ecological benefits and, b) where the causes of degradation can realistically be mitigated by river restoration strategies and projects. The third priority is to focus monitoring and assessment efforts in regions that are relatively 'data poor' such as where too few assessments have been conducted for statistical analysis of change between the 1990s and 2000s to be computed reliably. A particular focus on improving the reliability of HQA and HIR measures would increase our understanding of national habitat quality trends.

Prioritising river restoration is a balance between identifying opportunities to improve ecosystem functions and services, and pragmatism. Of those 27 Local Authorities identified where habitat condition has substantially declined over the past two decades (Fig. 2), some may be more appropriate sites for future investment in restoration, while others may benefit from increased monitoring and assessment to determine the direction of change. Figure 3 presents a decision-making framework to inform investment with regards to sites where habitat quality has substantially declined.

The habitat condition dataset examined in this research offers an important opportunity to gain insight into the progress of river restoration efforts over the past two decades towards improving habitat condition, including the

Page $15 / 23$ 
quality of riparian vegetation and the morphological characteristics of river channels. However, landscapes and land use, particularly in urban areas, are changing rapidly. To accurately interpret our findings there is a need to consider the wider economic and social landscape of regions where habitat condition has improved compared to regions where condition has worsened or remained in a poor condition. It is likely that some negative Index of Change scores point to genuine opportunities to improve habitat quality, and over the longer term improve water quality. In other cases, scores may be indicative of major land use changes that are difficult to address through traditional river restoration strategies, and rather fall into the jurisdiction of urban planning. Similarly, it is likely that some improvements indicated by positive Index of Change scores reflect genuine successes of the river restoration sector, while others may more accurately signify areas where urban development is less viable and passive recovery, particularly of riparian vegetation, has occurred. Further, in some cases the changes observed in the dataset are the result of 'data poverty'. Unpacking these dynamics should be a priority for future research, as well as a means of allocating resources to improve habitat quality and achieve the objectives of the WFD in the UK.

\subsection{Achieving the objectives of the WFD}

Overall, our findings suggest that habitat quality has declined in the UK since the first WFD assessment. However, except for HIR, no other statistically significant changes were observed between the first WFD assessment and aggregate measures of habitat condition from assessments undertaken in the 2000s. For measures of HIR, the average condition of sites in regions scored in the WFD assessment as 'good', 'moderate' and 'poor' condition has declined, with the largest decline occurring in regions with sites previously scored as 'in good condition'. Thus, the challenge for future river management is two-pronged; improving degraded sites as well as preserving high-quality sites. These findings are consistent with parallel measures of river quality. For example, a recent assessment undertaken by the Environment Agency, including pollutants, water quality and the number of small animals found in rivers found that only $14 \%$ of rivers meet the Good Ecological Status outlined in the Water Framework Directive (Bevan 2020). The HQA index analysed in our research refers to overall habitat diversity in stream considering natural channel features that are conducive to supporting habitat diversity. Thus, our observations reflect the results of the EA assessment about the structure and functioning of riverine ecosystems (European Environment Agency 2018). Our observations about how well restoration efforts are achieving the objectives of the WFD in relation to habitat condition in the UK are not unique. Many regions in Europe are struggling to effectively implement the WFD, with key challenges including economic viability and the difficulties associated with multi-level governance (Bouleau 2008; Berbel \& Expósito 2018; Maia 2017). Further research is required to elucidate the institutional factors that may explain the decline of habitat quality in the UK compared to condition at the time of the WFD assessment in 2000.

\subsection{Strengths and limitations}

The UK river restoration sector is incredibly data rich. However, there are inherent challenges with retrospectively analysing 'messy' routinely collected observational data, such as the habitat condition database presented here. There is a need to develop consistent guidelines for the use of observational data in the river restoration sector. This study does not represent a controlled trial or an experimental 'before/after' study design in the truest sense. Few changes at the LA scale are statistically significant. Thus, interpreting our results requires a balance of caution and optimism; our findings reflect wider trends in water quality and resource condition documented elsewhere (e.g., Haines-Young et al. 2000; Smart et al. 2008). However, our findings regarding 'worst' and 'best' condition LAs should be considered cautiously. The need for caution does not diminish the value of analysing observation datasets (Vaughan \& Ormerod, 2010), but, rather, points to future avenues for improving data collection.

In most cases, the sites assessed within an LA during the 1990s assessment period were different to the sites assessed within the same LA in the 2000s. Therefore, we aggregated the Index of Change scores within LAs for comparative analysis. While aggregation reduces the complexity and richness of the dataset, this approach is not unprecedented 
(e.g., Moore \& Rutherfurd, 2019; VCMC, 2017). Monitoring and assessment are rarely conducted empirically or consistently within or between regions (Kondolf, 2007; Bernhardt et al. 2007). Some degree of aggregation or collapsing is usually required to make regional comparisons. A further challenge of using the RHS data to explore the progress of river restoration in the UK is the characteristics of measures. In particular, the RQI related to riparian vegetation does not distinguish between native versus invasive species. Thus, while an indicator of morphological recovery (e.g., bank stabilisation) it is difficult to determine the ecological value of riparian vegetation.

To counteract the limitations of aggregation, we integrated spatial and statistical analysis, facilitating a more in-depth interpretation of the Index of Change. Visually displaying the RHS data allowed us to examine spatial trends that are not immediately apparently from statistical analysis alone. Spatial analysis illuminated important geographic differences between regions with negative Index of Change scores across different measures of habitat condition.

\section{Conclusions}

A critique of the early decades of river restoration in Europe is a lack of strategy and coordinated investment to improve the condition of degraded environmental assets (Szałkiewicz et al. 2018). After more than three decades of implementation there is a need to assess progress in order to facilitate more targeted investment in high-valued ecological services and features of natural landscapes. Domestic efforts to restore degraded ecosystems encompass the dual challenge of implementing projects that satisfy national priorities at the same time as achieving the goals of international initiatives, such as the WFD (Wharton \& Gilvear 2007). In the wake of BREXIT, the endeavours and commitments set in motion by the European Union remain a cornerstone of best practice that should be honoured and upheld. We evaluated trends in habitat condition over two decades in the UK to determine whether restoration projects are having the desired effect on riverine ecosystems. We make four observations from this analysis: firstly, habitat condition has declined on all measures except riparian quality; secondly, while the legacy of river modification has severely impacted both the ecological and geomorphological characteristics of habitats, ecological conditions may have declined to a greater degree in recent years; thirdly, change in condition has not progressed in the desired direction since the initial assessment conducted under the WFD; and fourthly, these trends are not homogenous - some regions have declined more substantially than others.

Finally, we offer some guidance to optimise the benefits of future investment to improve habitat and water quality. As a preliminary step, further local and regional scale research is needed to address the current data deficit in many LAs, and to elucidate the underlying causes of condition decline. Where possible, efforts should be targeted to establishing best management catchment practices in regions where conditions have declined. However, in some cases degradation may be related to wider land use changes. Thus, there is a need to coordinate efforts alongside urban planning and landscape design, particularly in rapidly expanding urban areas. In a post-BREXIT world, the purpose of the WFD remains relevant, safeguarding water and ecosystems for a sustainable future.

\section{Declarations}

Funding: N/A

Conflicts of interest: The authors declare no competing interests or conflicts of interest.

Ethics approval: Data access was permitted through a formal agreement with the River Restoration Centre.

Consent to participate: N/A

Consent for publication: N/A

Page $17 / 23$ 
Availability of data and material: We are unable to provide the data used for the research due to our access agreement with the River Restoration Centre. However, we are able to provide extensive supplementary material including the output of all statistical analyses.

Code availability: N/A

Authors contributions: All authors contributed to concept development. Dr Moore contributed to the introduction, methodology, data analysis, field work, results, and drafted the discussion of the manuscript. Dr Mercer contributed to the introduction, methodology, data analysis, field work, and edited the entire manuscript. Dr Alwis Pitts contributed to the methodology, data analysis and the production of spatial figures. Mr Beagley contributed to data analysis and methodology and discussion. Mr Naura contributed to the development of methodology, conducted several edits of the entire manuscript, and contributed to data analysis. Ms. Bryden contributed to field work, data analysis and editing manuscript drafts.

\section{References}

Acuña GJ, Ávila H, Canales FA (2019) River Model Calibration Based on Design of Experiments Theory. A Case Study: Meta River, Colombia. Water 11:1382

Beechie, T., Pess, G., Roni, P. and Giannico, G., 2008. Setting river restoration priorities: a review of approaches and a general protocol for identifying and prioritizing actions. North American Journal of Fisheries Management, 28(3), pp.891-905.

Berbel J, Expósito A (2018) Economic challenges for the EU Water Framework Directive reform and implementation. European Planning Studies 26:20-34

Bernhardt ES et al. (2007) Restoring rivers one reach at a time: Results from a survey of U.S. river restoration practitioners. Restoration Ecology 15:482-493

Bernhardt ES et al. (2005) Synthesizing U.S. River Restoration Efforts.

Bevan J (2020) The state of our waters: the facts - Creating a better place. Environment Agency - The state of our waters: the facts

Bouleau G (2008) The WFD dreams: between ecology and economics. Water and Environment Journal 22:235-240

Brooks SS, Lake PS (2007) River restoration in Victoria, Australia: Change is in the wind, and none too soon.

Restoration Ecology 15:584-591

Cashman MJ et al. (2019) Trends in the use of large wood in UK river restoration projects: insights from the National River Restoration Inventory. Water and Environment Journal 33:318-328

Coulthard TJ, Macklin MG (2003) Modeling long-term contamination in river systems from historical metal mining. GeoScienceWorld

Dawson D et al. (2015) Long-term trends in reservoir water quality and quantity in two major river basins of the southern Great Plains. Lake and Reservoir Management 31:254-279

DEFRA (2018) A green future: our 25 year plan to improve the environment. 
Dosskey MG et al. (2010) The role of riparian vegetation in protecting and improving chemical water quality in streams. Journal of the American Water Resources Association 46:261-277

England J et al. (2019) Seeking river restoration appraisal best practice: supporting wider national and international environmental goals. Water and Environment Journal 1-9

Erskine WD, Webb AA (2003) Desnagging to resnagging: new directions in river rehabilitation in southeastern Australia. River Research and Applications 19:233-249

European Environment Agency (2018) Ecological status of surface water bodies - European Environment Agency.

Fernández D, Barquín J, Raven PJ (2011) A review of river habitat characterisation methods: indices vs. characterisation protocols. Limnetica 29:217-234

Fox PJA, Naura M, Scarlett P (1998) An account of the derivation and testing of a standard field method, River Habitat Survey. Aquatic Conservation: Marine and Freshwater Ecosystems 8:455-475

Frostick LE, McLelland S, Mercer TG (2011a) Chapter 1: Introduction. In: A Users Guide to Hydraulic Modelling and Experimentation. Frostick, LE, McLelland, SJ, \& Mercer, TG, editors. IAHR Publications.

Frostick LE, McLelland S, Mercer TG (2011b) Chapter 5: Ecological Experiments. In: A Users Guide to Hydraulic Modelling and Experimentation. Frostick, LE, McLelland, SJ, \& Mercer, TG, editors. IAHR Publications.

Grabowski RC, Gurnell AM (2016) Hydrogeomorphology-Ecology Interactions in River Systems. River Research and Applications 32:139-141

Gurnell AM et al. (2016) A multi-scale hierarchical framework for developing understanding of river behaviour to support river management. Aquatic Sciences 78:1-16

Haines-Young RH et al. (2000) Accounting for nature: assessing habitats in the UK countryside. London

Hamilton SK (2012) Biogeochemical time lags may delay responses of streams to ecological restoration. Freshwater Biology 57:43-57

Hammond D et al. (2011) Practical River Restoration Appraisal Guidance for Monitoring Options (PRAGMO). The River Restoration Centre (RRC) 330

Harper DM et al. (1999) A catchment-scale approach to the physical restoration of lowland UK rivers. Aquatic Conservation: Marine and Freshwater Ecosystems 9:141-157

Heatherly T et al. (2007) Relationships between Water Quality, Habitat Quality, and Macroinvertebrate Assemblages in Illinois Streams. Journal of Environmental Quality 36:1653-1660

Hubble TCT, Docker BB, Rutherfurd ID (2010) The role of riparian trees in maintaining riverbank stability: A review of Australian experience and practice. Ecological Engineering 36:292-304

Hulme, P.E. and Bremner, E.T., 2006. Assessing the impact of Impatiens glandulifera on riparian habitats: partitioning diversity components following species removal. Journal of Applied Ecology, 43(1), pp.43-50.

Jansson, R., Nilsson, C. and Malmqvist, B., 2007. Restoring freshwater ecosystems in riverine landscapes: the roles of connectivity and recovery processes. Freshwater Biology, 52(4), pp.589-596. 
Jenkinson RG et al. (2006) Stream Restoration Databases and Case Studies: A Guide to Information Resources and Their Utility in Advancing the Science and Practice of Restoration. Restoration Ecology 14:177-186

Kingsford RT (2000) Ecological impacts of dams, water diversions and river management on floodplain wetlands in Australia. Austral Ecology 25:109-127

Kondolf GM et al. (2007) Two Decades of River Restoration in California: What Can We Learn? Restoration Ecology $15: 516-523$

Lutz SR et al. (2016) Hydroclimatic and water quality trends across three Mediterranean river basins. Science of the Total Environment 571:1392-1406

Macklin MG et al. (2006) A geomorphological approach to the management of rivers contaminated by metal mining. Geomorphology 79:423-447

Maia R (2017) The WFD Implementation in the European Member States. Water Resources Management 31:30433060

McKinney, M.L., 2008. Effects of urbanization on species richness: a review of plants and animals. Urban ecosystems, 11(2), pp.161-176.

Meals DW, Dressing SA, Davenport TE (2010) Lag Time in Water Quality Response to Best Management Practices: A Review. Journal of Environmental Quality 39:85-96

Mercer EV, Mercer TG, Sayok AK (2014) Effects of forest conversions to oil palm plantations on freshwater macroinvertebrates: a case study from Sarawak, Malaysia. Journal of Land Use Science 9:260-277

Moore HE, Rutherfurd ID (2017) Lack of maintenance is a major challenge for stream restoration projects. River Research and Applications 33:1387-1399

Moore HE, Rutherfurd ID (2019) Using voluntary agreements to exclude stock from waterways: An evaluation of project success and persistence. Integrated Environmental Assessment and Management 15:237-247

Moore HE, Rutherfurd ID, Peel MC (2018) Excluding stock from riverbanks for environmental restoration: The influence of social norms, drought, and off-farm income on landholder behaviour. Journal of Rural Studies 62:116-124

Morandi B et al. (2014) How is success or failure in river restoration projects evaluated? Feedback from French restoration projects. Journal of Environmental Management 137:178-188

O’Brien T et al. (2010) Review of fishways in Victoria 1996-2009. Arthur Rylah Institute for Environmental Research Technical Report Series No. 216. Heidelberg, Victoria

Palmer M et al. (2007) River restoration in the twenty-first century: Data and experiential knowledge to inform future efforts. Restoration Ecology 15:472-481

Palmer MA et al. (2008) Climate change and the world's river basins: Anticipating management options. Frontiers in Ecology and the Environment 6:81-89

Palmer MA, Menninger HL, Bernhardt E (2010) River restoration, habitat heterogeneity and biodiversity: A failure of theory or practice? Freshwater Biology 55:205-222

Page 20/23 
Parkyn S et al. (2010) The Restoration Indicator Toolkit. Indicators for Monitoring the Ecological Success of Stream Restoration.

Raven PJ et al. (1998) Quality assessment using River Habitat Survey data. Aquatic Conservation: Marine and Freshwater Ecosystems 8:477-499

Raven PJ et al. (2000) Using river habitat survey for environmental assessment and catchment planning in the U.K. Hydrobiologia 422/423:359-367

Reid AJ et al. (2019) Emerging threats and persistent conservation challenges for freshwater biodiversity. Biological Reviews 94:849-873

Ridding, L.E., Watson, S.C., Newton, A.C., Rowland, C.S. and Bullock, J.M., 2020. Ongoing, but slowing, habitat loss in a rural landscape over 85 years. Landscape Ecology, 35(2), pp.257-273.

River Restoration Centre (2018) National River Restoration Inventory (NRRI).

River Restoration Centre (2014). Manual of River Restoration Techniques, https://www.therrc.co.uk/manual-riverrestoration-techniques, viewed 14 January 2021.

Robertson DJ, Coll M (2019) Effects of Riparian Invasive Nonindigenous Plants on Freshwater Quantity and Ecological Functioning in Mesic Temperate Landscapes. Natural Areas Journal 39:22

RRC (2020) River Habitat Survey Indices Summary.

Smart J et al. (2008) Changing land management of lowland wet grasslands of the UK: impacts on snipe abundance and habitat quality. Animal Conservation 11:339-351

Smith B, Clifford NJ, Mant J (2014) Analysis of UK river restoration using broad-scale data sets. Water and Environment Journal 28:490-501

de Sosa LL et al. (2018) Riparian research and legislation, are they working towards the same common goals? A UK case study. Environmental Science and Policy 82:126-135

Stone ML et al. (2005) Macroinvertebrate Communities in Agriculturally Impacted Southern Illinois Streams: Patterns with Riparian Vegetation, Water Quality, and In-Stream Habitat Quality. Journal of Environmental Quality 34:907-917

Szałkiewicz E, Jusik S, Grygoruk M (2018) Status of and Perspectives on River Restoration in Europe: 310,000 Euros per Hectare of Restored River. Sustainability 2018, Vol. 10, Page 129 10:129

Vaughan IP, Ormerod SJ (2010) Linking ecological and hydromorphological data: approaches, challenges and future prospects for riverine science. Aquatic Conservation: Marine and Freshwater Ecosystems 20:125-130

VCMC. 2017. Publications. http://www.vcmc.vic.gov.au/publications.htmIVidon PG, Welsh MK, Hassanzadeh YT (2019) Twenty Years of Riparian Zone Research (1997-2017): Where to Next? Journal of Environmental Quality 48:248-260

Ward J et al. (2006) Market-based instrument approaches to implementing priority revegetation in the South Australian Murray-Darling Basin (No. 417-2016-26395). 
Wharton G, Gilvear DJ (2007) River restoration in the UK: Meeting the dual needs of the European union water framework directive and flood defence? International Journal of River Basin Management 5:143-154

Wohl E, Lane SN, Wilcox AC (2015) The science and practice of river restoration. Water Resources Research 51:59745997

Yao W-W et al. (2017) Habitat models for assessing river ecosystems and their application to the development of river restoration strategies. Journal of Freshwater Ecology 32:601-617

\section{Figures}

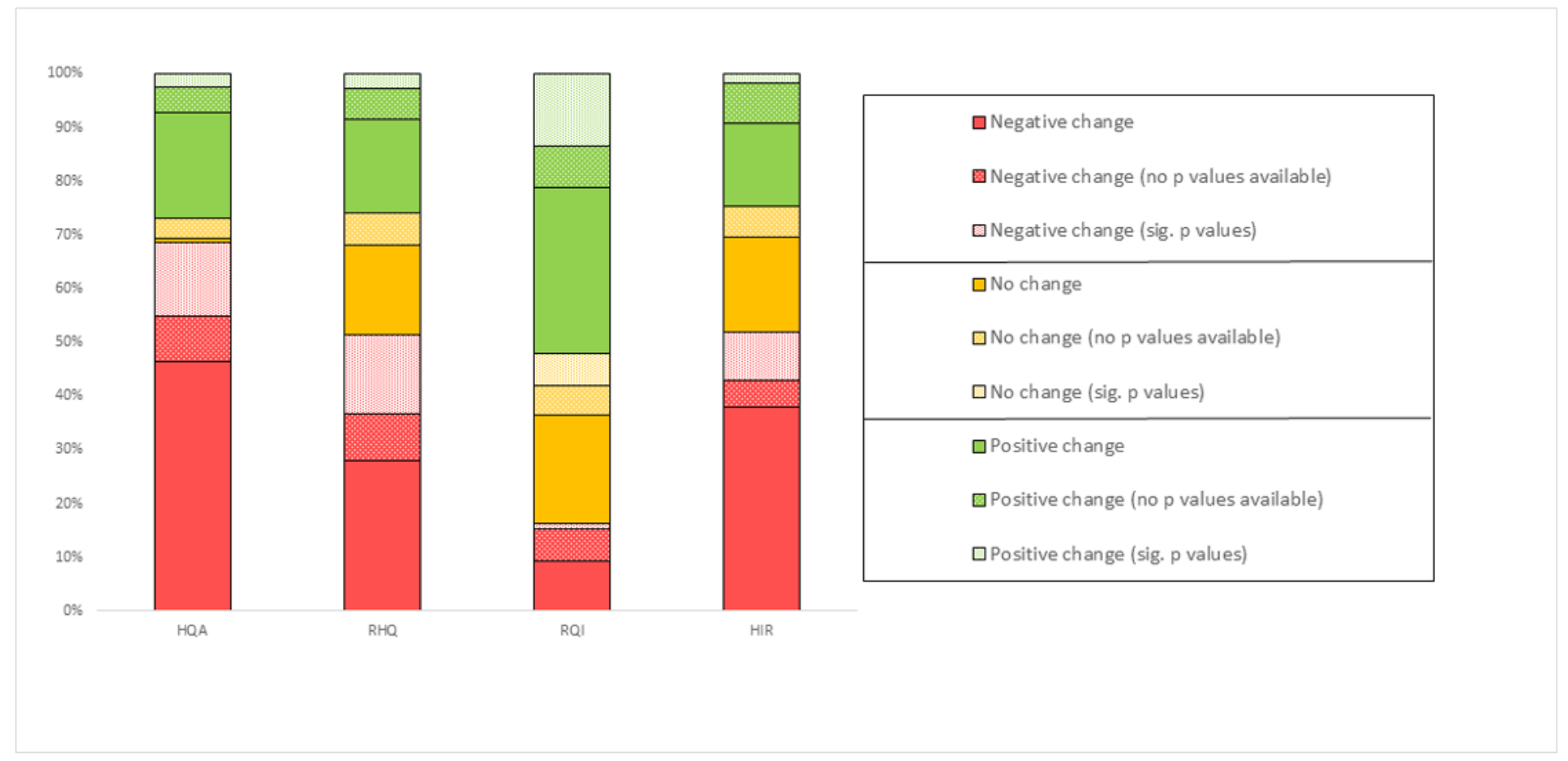

Figure 1

Percentage of positive, neutral or negative change scores for RHS quality measures at the Local Authority Scale.

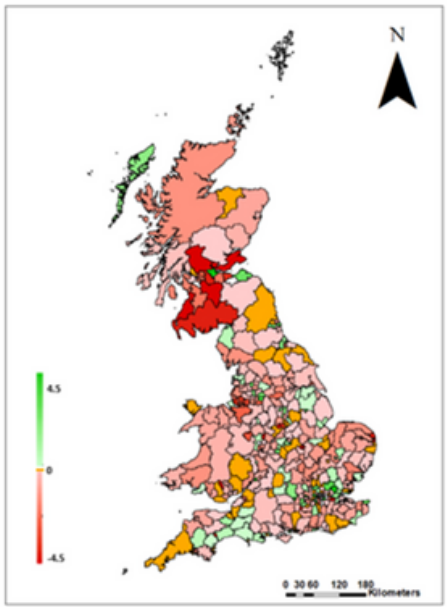

a.) HQA

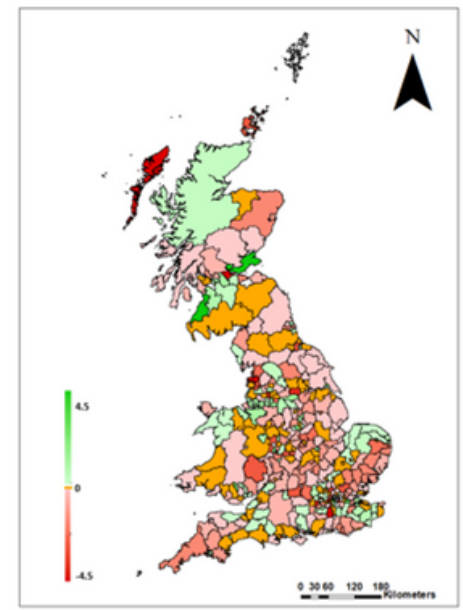

b.) $\mathrm{RHQ}$

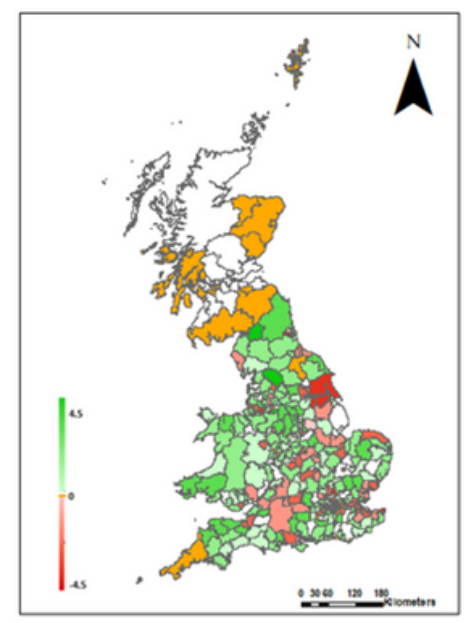

c.) $\mathrm{RQI}$

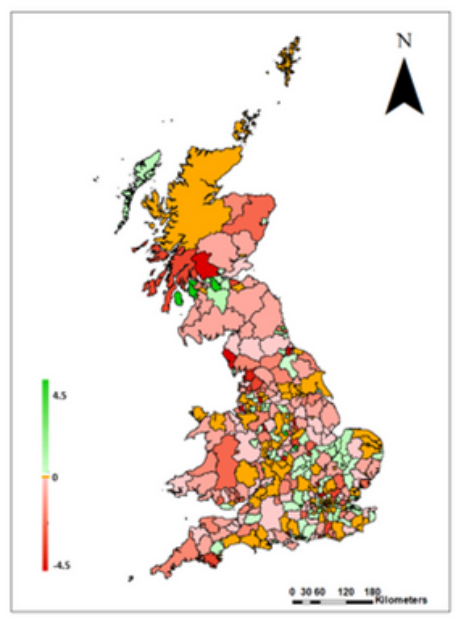

d.) HIR

Figure 2 
Spatial representation of Index of Change for, a) Habitat Quality Assessment (HQA), b) River Habitat Quality (RHQ), c) Riparian Quality Index (RQI) and d) Hydromorphological Impact Ratio (HIR). Green areas represent positive changes, red areas represent negative changes, orange represents no change and white represents areas where there is data missing; no surveys were undertaken in Scotland and Northern Ireland in the 2000s.

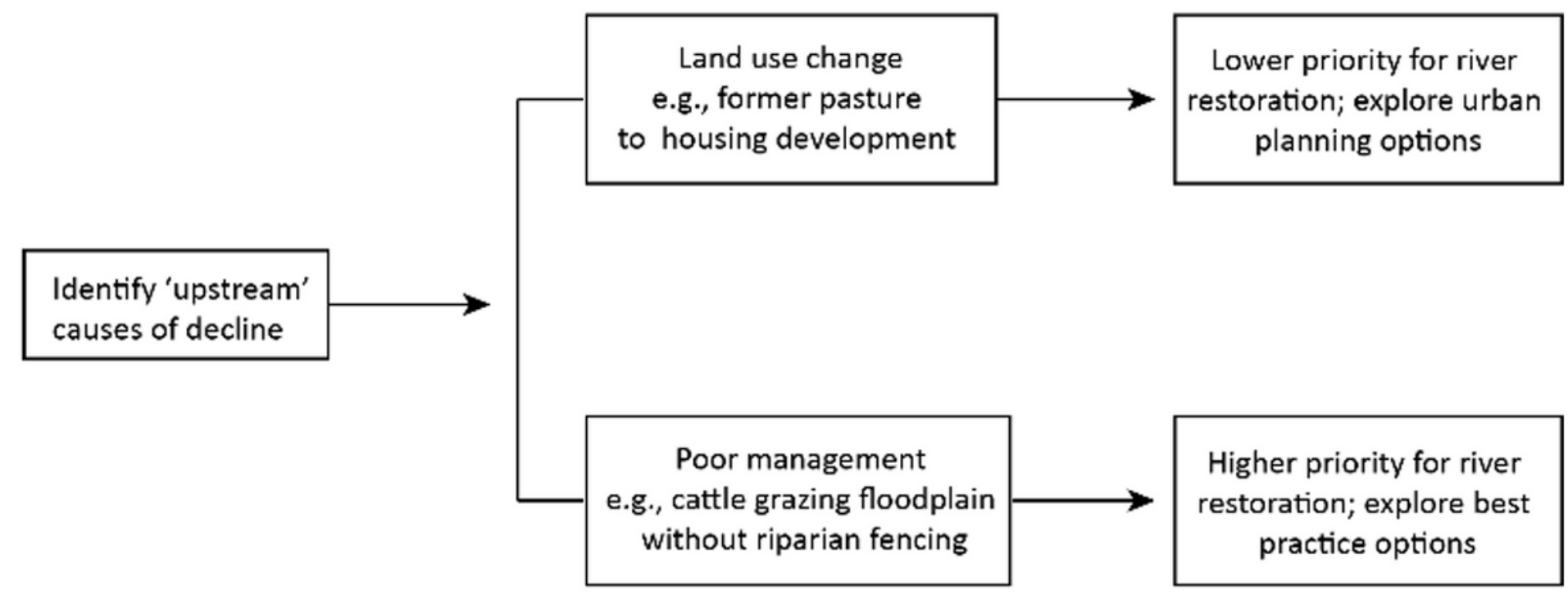

Figure 3

Schematic decision-making framework for prioritising investment in local authority regions where habitat quality has declined between RHS assessments conducted in the 2000s compared to RHS assessments conducted in the 1990s.

\section{Supplementary Files}

This is a list of supplementary files associated with this preprint. Click to download.

- CopyofRHSstatsChangetable1NEW.xIsx

- SuppmaterialFINAL.docx 